\title{
Investigation of drought propagation in South Korea using drought index and conditional probability
}

\author{
Ji Yae Shin ${ }^{1}$, Si Chen ${ }^{1}$, Joo-Heon Lee ${ }^{2}$, and Tae-Woong Kim ${ }^{3, *}$ \\ ${ }^{I}$ Department of Civil and Environmental Engineering, Hanyang University, Seoul, Republic of Korea \\ ${ }^{2}$ Department of Civil Engineering, Joongbu University, Goyang, Republic of Korea \\ ${ }^{3}$ Department of Civil and Environmental Engineering, Hanyang University, Ansan, Republic of Korea
}

\begin{abstract}
Article history:
Received 25 March 2017

Revised 2 July 2017

Accepted 23 August 2017

Keywords:

Drought propagation, Standardized Precipitation Index, Palmer Hydrological Drought Index, Conditional probability

Citation:

Shin, J. Y., S. Chen, J.-H. Lee, and T.-W. Kim, 2018: Investigation of drought propagation in South Korea using drought index and conditional probability. Terr. Atmos. Ocean. Sci., 29, 231-241, doi: 10.3319/ TAO.2017.08.23.01
\end{abstract}

\begin{abstract}
Meteorological drought commonly originates from precipitation deficit and is then propagated to agricultural and hydrological droughts. Since drought impacts are more directly related to agricultural and hydrological systems of human society, it is important to understand the drought propagation process for reducing drought impacts. This study investigated the propagation of meteorological droughts through the hydrological system in South Korea. We performed comparative analyses between a meteorological drought indicator [Standardized Precipitation Index (SPI) at various timescales] and a hydrological drought indicator [Palmer Hydrological Drought Index (PHDI)], and pooled the mutually dependent drought events from the indicators. The results indicated that most hydrological droughts occurred following meteorological droughts, and drought events became fewer and longer when moving from 3- and 6-month SPI to PHDI. In addition, when we investigated the meteorological conditions, about $70-80 \%$ of 3- and 6-month SPI corresponding to the onset of hydrological drought (PHDI $\leq-2$ ) were less than -1.0 . We also calculated the propagation probability using the conditional probability theory with $33 \%$ (3-month SPI) and 48\% (6-month SPI) of meteorological droughts propagated to hydrological drought. We concluded that even though the frequency of hydrological drought in South Korea was less than that of meteorological drought, the severity of hydrological drought was greater than that of meteorological drought.
\end{abstract}

\section{INTRODUCTION}

Drought is a complex natural disaster that occurs when various hydro-meteorological variables become drier than the normal condition. Considering various perspectives and interests, drought is generally classified into four categories: meteorological, agricultural, hydrological, and socioeconomic (Wilhite and Glantz 1985). The primary cause of drought is the lack of precipitation over a large area for a long time. A meteorological drought is usually defined based on the degree of dryness and the duration of the dry period, which is a departure from the normal precipitation of the region. Meanwhile, precipitation deficit is propagated through surface and subsurface regions, developing into agricultural and hydrological droughts (Wilhite 2000; Van Lanen 2006). An agricultural drought is one where the

\footnotetext{
* Corresponding author

E-mail:twkim72@hanyang.ac.kr
}

drought impact mostly affects agriculture such as soil moisture deficits, while a hydrological drought usually occurs following periods of extended precipitation shortfalls that affect surface or subsurface water supply. A socioeconomic drought is identified when the demand for an economic goods exceeds supply due to a weather-related shortfall in water supply.

The type of drought changes over time through drought propagation process. After introducing the concept of drought propagation by Changnon (1987), Van Loon (2015) defined drought propagation as the transition from meteorological to hydrological drought. Since atmosphere, surface and subsurface water storages are closely interconnected within the hydrologic cycle, meteorological, agricultural, and hydrological droughts are related with each other. Some studies have tried to find correlations and/or causal relationships between different drought types (Zhai et al. 
2010; Joetzjer et al. 2013; Wong et al. 2013; Haslinger et al. 2014; Thomas et al. 2015; Zhu et al. 2016), and have concluded that there is a significant link between different drought types. For example, Haslinger et al. (2014) estimated the correlation of four meteorological drought indices [SPI, Standardized Precipitation Evapotranspiration Index (SPEI), Z-index and self-calibrating Palmer Drought Severity Index (scPDSI)] with streamflow. Their results showed that the correlation with scPDSI in the dry season from August to October yielded the best performance.

Relatively, few studies have attempted to understand the drought propagation process using the hydro-meteorological drought variables (Van Loon and Van Lanen 2012; Zhao et al. 2014; Barker et al. 2016; Melo and Wendland 2016; Wang et al. 2016) due to the complex mechanism behind the drought propagation procedures. Zhao et al. (2014) compared the SPI and Standardized Runoff Index (SRI) to detect the propagation of meteorological drought to streamflow drought, as well as with hydrological drought. They found that streamflow drought lagged behind meteorological drought. In addition, the frequency and magnitude of streamflow drought became lower and greater, respectively, than that of meteorological drought. Van Loon and Van Lanen (2012) found primary features of drought propagation (pooling, attenuation, lag, and lengthening) after investigating drought propagation using meteorological variables (precipitation and temperature) and simulated hydrological variables (soil moisture, groundwater, and discharge). Melo and Wendland (2016) applied the change point to estimate the time lag between meteorological drought shift and reservoir storage. Several drought propagation features and the propagation of meteorological variable anomalies in accordance with the hydrological drought type have been revealed; however, a statistical approach to show the drought propagation phenomenon has not been conducted.

This study aimed to illustrate drought propagation in South Korea using various drought indicators and to explain the relationship between meteorological and hydrological drought based on a statistical approach. In South Korea, drought studies are more widely performed using meteorological drought indices than hydrological drought indices (Min et al. 2003; Yoo et al. 2015; Kwon et al. 2016). Considering the difficulty assessing hydrological drought it is important to distinguish the different types of drought and underline the drought occurrence process in order to effectively manage droughts. In addition, knowledge of drought propagation is very beneficial to drought forecasting for effective drought management. Therefore, the study of drought propagation is required in South Korea.

We compared various timescales of SPI (as a meteorological drought indicator) and PHDI (as a hydrological drought indicator) to detect the critical condition of drought propagation in South Korea. Then we analyzed the hydrological drought occurrence probabilities under the meteo- rological condition to understand the drought propagation pattern. The occurrence probability of drought propagation can be estimated by the conditional probability of transition from meteorological to hydrological drought.

\section{STUDY AREA AND DATA}

\subsection{Study Area}

This study collected precipitation and temperature data at 35 weather stations in South Korea from the Korea Meteorological Administration (KMA), as shown in Fig. 1. The KMA provided daily precipitation and temperature data from 1973 - 2015. In South Korea, drought is the most constantly and widely occurring natural disaster, occurring approximately once every year (Kwak et al. 2014). Since more than $50 \%$ of annual rainfall is concentrated during the flood season from June to early September drought is mostly experienced in the dry spring season.

\subsection{Meteorological Drought Index}

In this study, a meteorological drought was identified by SPI, because the SPI computation is based only on precipitation and can describe drought on multiple timescales (Belayneh et al. 2014). SPI was developed by McKee et al. (1993) for estimating the precipitation deficits on multiple timescales. In this study, firstly, after aggregating daily data into monthly data, the long-term precipitation record at monthly time scales (or accumulation period of 3,6 , or 12 months) was fitted to a two-parameter gamma distribution defined by Eq. (1).

$$
f(x ; \alpha, \beta)=\frac{1}{\beta^{\alpha} \int_{0}^{\infty} x^{\alpha-1} e^{-x} d x} x^{\alpha-1} e^{-x / \beta}, \text { for } x>0
$$

where $x$ is the precipitation on multiple timescales, $\alpha$ is the shape parameter and $\beta$ is the scale parameter. We determined the parameters using the maximum likelihood method (MLM), which is the most widely used method for estimating parameters that maximize the likelihood of the given data. The fitted gamma distribution was transformed into the standard normal distribution with zero mean and one standard deviation to overcome the discrepancy results (Zargar et al. 2011). This distribution transformation made the mean of SPI zero at any location and time scales. The SPI is classified into seven categories of dry/wet conditions (Table 1) and denotes a drought event when a value of SPI is less than -1.0 .

\subsection{Hydrological Drought}

In this study, a hydrological drought was identified by 
PHDI, which has been used to assess the long-term impact of drought on hydrological systems (Vicente-Serrano et al. 2012). The PHDI was derived from the PDSI, which was based on a primitive water balance model. The PDSI, PHDI, and $\mathrm{Z}$ index are referred as the Palmer index (Heim 2002) to assess the moisture anomaly, and they are identified during the PDSI calculation describe in Palmer (1965). The PDSI is the moisture anomaly between actual and normal precipitation, in which the normal precipitation is climatologically appropriate for the existing conditions (CAFEC). The
CAFEC precipitation $\left(\widehat{P}_{i}\right)$ is computed by the water balance equation considering four hydrological components (evapotranspiration, runoff, soil moisture loss, and recharge).

$$
\widehat{P}_{i}=\alpha_{j} P E+\beta_{j} P R+\gamma_{j} P R O+\delta_{j} P L
$$

where, $j$ indicates the calendar month $(j=1, \ldots, 12)$ and $i$ is the index of month $[i$ is calculated as $12(y-1)+j$ for $y$ th year and $j$ th month]. $P E$ is the potential evapotranspiration, $P R$ is

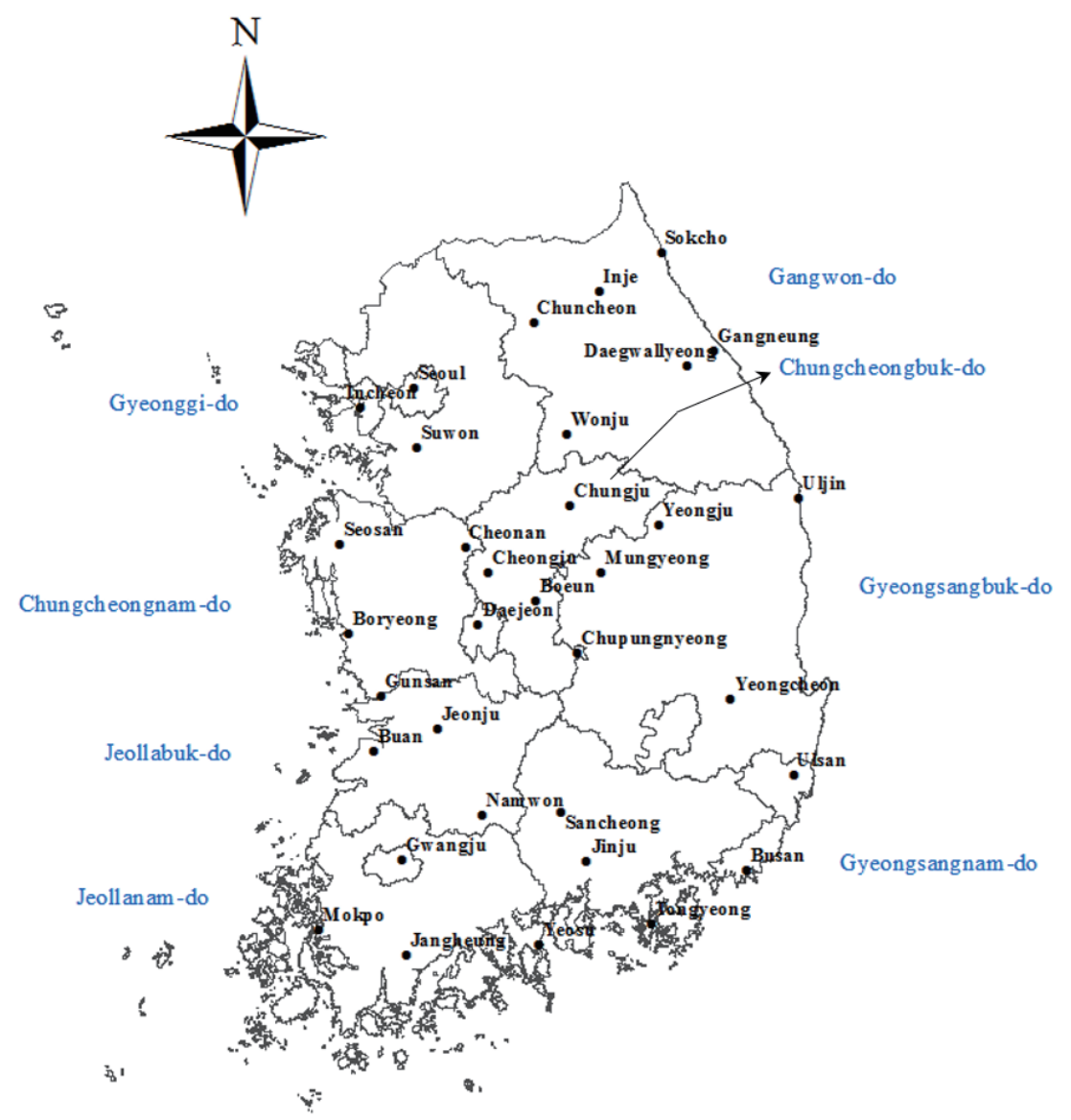

Fig. 1. Weather stations for which precipitation and temperature data used in study.

Table 1. Classifications of dry/wet condition in accordance with the PHDI and SPI.

\begin{tabular}{ccc}
\hline Categories & PHDI & SPI \\
\hline Extremely dry & $\leq-4.0$ & $\leq-2.0$ \\
Severely dry & $-3.99 \sim-3.00$ & $-1.99 \sim-1.50$ \\
Moderately dry & $-2.99 \sim-2.00$ & $-1.49 \sim-1.00$ \\
Near normal & $-1.99 \sim 1.99$ & $-0.99 \sim 0.99$ \\
Moderately wet & $2.00 \sim 2.99$ & $1.00 \sim 1.49$ \\
Severely wet & $3.00 \sim 3.99$ & $1.50 \sim 1.99$ \\
Extremely wet & $\geq 4.0$ & $\geq 2.0$ \\
\hline
\end{tabular}


the potential recharge, $P R O$ is the potential runoff, and $P L$ is the potential water loss from the soil. $\alpha_{j}, \beta_{j}, \gamma_{j}$, and $\delta_{j}$ are coefficients for potential components, as given in Eq. (3).

$\alpha_{j}=\frac{\overline{E T}_{j}}{\overline{P E_{j}}}$

$\beta_{j}=\frac{\bar{R}_{j}}{\overline{P R_{j}}}$

$\gamma_{j}=\frac{\overline{R O_{j}}}{\overline{P R O_{j}}}$

$\delta_{j}=\frac{\bar{L}_{j}}{\overline{P L_{j}}}$

where, $E T$ is the evapotranspiration, $R$ is the soil moisture recharge, $R O$ is the runoff, and $L$ is the water loss from the soil. The overbar denotes the monthly average over the period of recording.

The detail calculation procedure of the potential and actual components may be found in Palmer (1965), Weber and Kkemdirim (1998), and Jacobi et al. (2013). The moisture anomaly index $\left(Z_{i}\right)$ is defined by Eq. (4).

$Z_{i}=\left(P_{i}-\widehat{P}_{i}\right) K_{i}$

where, $Z_{i}$ is the moisture anomaly index. $P_{i}$ is actual precipitation and $\widehat{P}_{i}$ is the CAFEC precipitation. $K_{i}$ is a weighting factor determined from the climate record, which is estimated by Eq. (5).

$K_{i}=\frac{17.67}{\sum_{j=1}^{12} \overline{D_{j}} K_{j}^{\prime}} K_{i}^{\prime}$

$K_{i}^{\prime}=1.5 \log _{10}\left[\frac{\left(\overline{P E}_{i}+\bar{R}_{i}+\overline{R O}_{i}\right) /\left(\bar{P}_{i}+\bar{L}_{i}\right)+2.8}{\bar{D}_{i}}\right]+0.5$

where, $\bar{D}_{i}$ is the average moisture departure for the appropriate month. After estimating $K_{i}$ and $Z_{i}$, PDSI values are finally calculated using Eq. (6).

$X_{i}=0.897 X_{i-1}+\frac{1}{3} Z_{i}$

The PDSI is technically computed by three intermediate indices $\left(X_{1}, X_{2}\right.$, and $\left.X_{3}\right)$ for each month. $X_{1}$ is an incipient wet spell $\left(X_{1, i} \geq 0\right), X_{2}$ is an incipient drought $\left(X_{2, i} \leq 0\right)$, and
$X_{3}$ is the existing dry or wet spell $\left(\left|X_{3, i}\right| \geq 1\right)$. The PHDI is $X_{3, i}$ whenever the percent of moisture needed to estimate the spell is between 0 and 100 , while $X_{1, i}$ or $X_{2, i}$ is chosen during the onset of a wet or dry spell (Guttman 1991). The PHDI has a more stringent criterion for the termination of a drought or wet spell, which means that the drought condition is verified to the normal state slower than PDSI (Keyantash and Dracup 2002; Dai 2011). This smoother variation in performance is approximate for the assessment of hydrological drought (Dai 2011).

To assess hydrological drought using calculated hydrological drought indices, such as SRI, Surface Water Supply Index (SWSI), and Groundwater Resource Index (GRI), long term observed streamflow data are required. However, in South Korea, most gauging stations have very limited observations of streamflow and groundwater which are less than 30 years and contain lot of missing data. Therefore, as an alternative, we applied the PHDI, which can be easily calculated using only temperature and precipitation provided by KMA, to estimate hydrological drought.

\section{RESULTS}

\subsection{Comparison Between Meteorological and Hydrological Drought}

The SPI and PHDI were calculated using monthly precipitation and temperature data. The SPIs at different time scales reflect various kinds of drought. Usually, a 1-, 3-, and 6-month SPI can reflect meteorological drought; however, SPI can be deployed for longer time scales (e.g., 9- and 12-month time scales) to reflect agricultural and hydrological droughts. Therefore, we applied three SPI accumulation periods (1-, 3-, and 6-month) to measure meteorological drought, whereas hydrological drought was described by PHDI. Drought events were defined when the SPI fell below -1.0 and PHDI below -2.0, as given in Table 1 .

We compared two types of drought indicators to investigate when drought propagation occurred. Figure 2 illustrates a representative example sequence of drought states defined by SPI at different time scales and PHDI, indicating no drought condition (SPI $<-1.0$ and PHDI $<-2.0$ ) with a white color and drought conditions with orange, red and black colors with severity in ascending order. The comparative analysis between SPI at various time scales and PHDI showed a good description of drought propagation features. For example, the transition from meteorological to hydrological drought was identified in the 1988 drought event. The short duration meteorological drought was first identified with the 1-month SPI. Afterwards, the 3- and 6-month SPI represented the drought condition in sequence, and then the 12-month SPI and PHDI reflected the hydrological drought observed last. From Fig. 2, we found that drought events in 1977, 1980 - 1982, 1988, 1992, 1994, 1996, 2001, and 2014 - 2015 have propagated from the short-term SPI 
to the PHDI. Figure 2 also shows that not all meteorological droughts identified by the 3- and 6-month SPI resulted in hydrological droughts during 2004 and 2006.

Based on the time series of drought shown in Fig. 2, two examples of drought propagation were extracted. The SPI (3-, 6-, and 12-month) and PHDI time series during the hydrological drought periods are presented in Fig. 3. For the 1988 drought example (Fig. 3a), the drought onset of 3- and 6-month SPI led to another drought onset of PHDI and 12-month SPI showed a time lag with the PHDI. For the 1994 example (Fig. 3b), 3-month SPI also preceded the drought onset of PHDI, while the 6- and 12-month SPI drought occurred at the same time as that of PHDI. Zhao et al. (2014) concluded that 12-month SPI was unsuitable for early warning of hydrological drought since it happened after the start of hydrological drought or at the same time. Our work also found that the onset of drought with 12-month SPI did not precede the drought with PHDI and thus could not monitor hydrological drought. To define an independent sequence of droughts, mutually dependent droughts (e.g.,

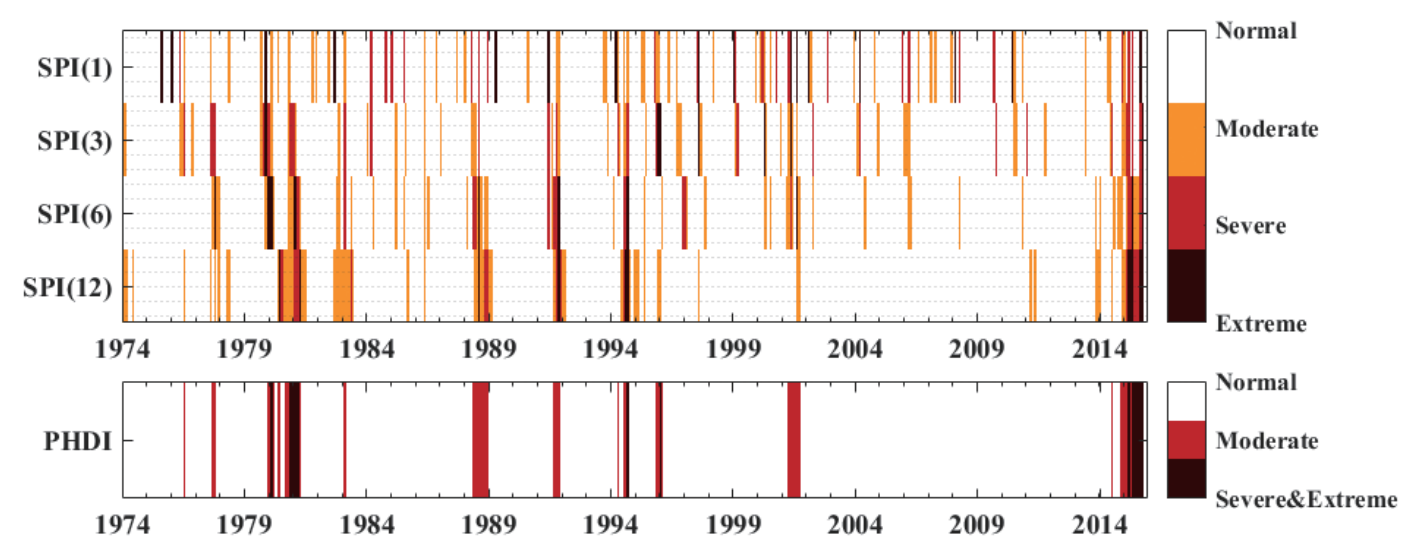

Fig. 2. Drought states with the accumulation timescales of SPI and PHDI at Sokcho station.

(a)
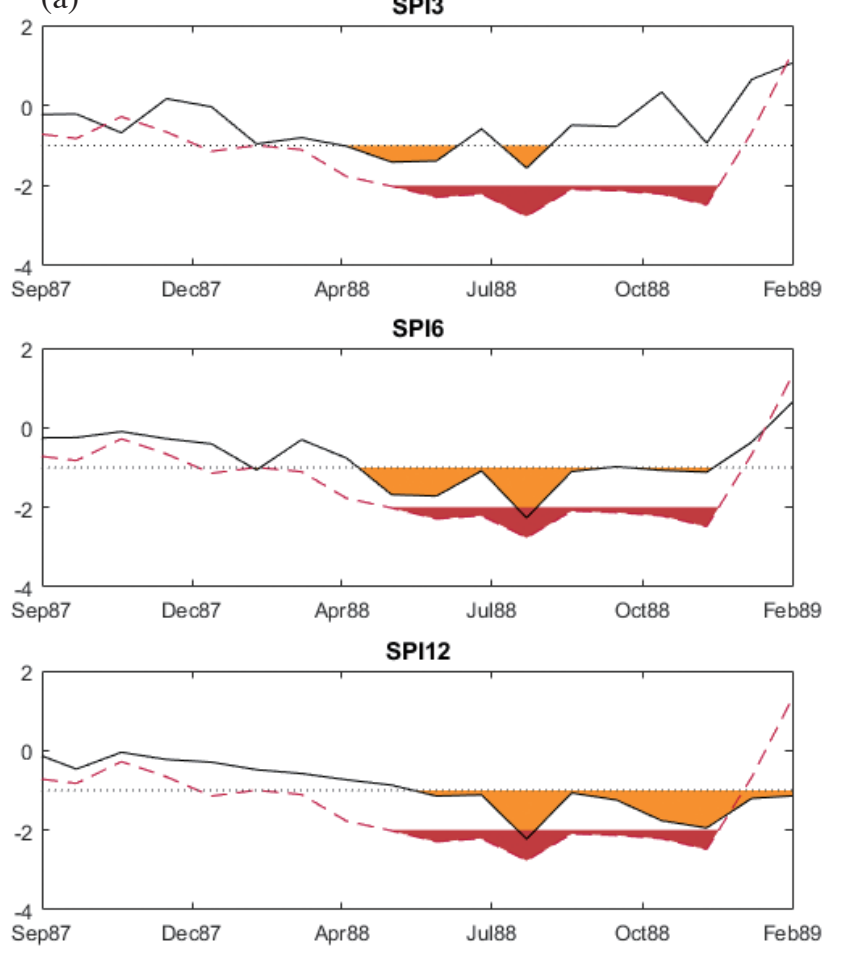

(b)
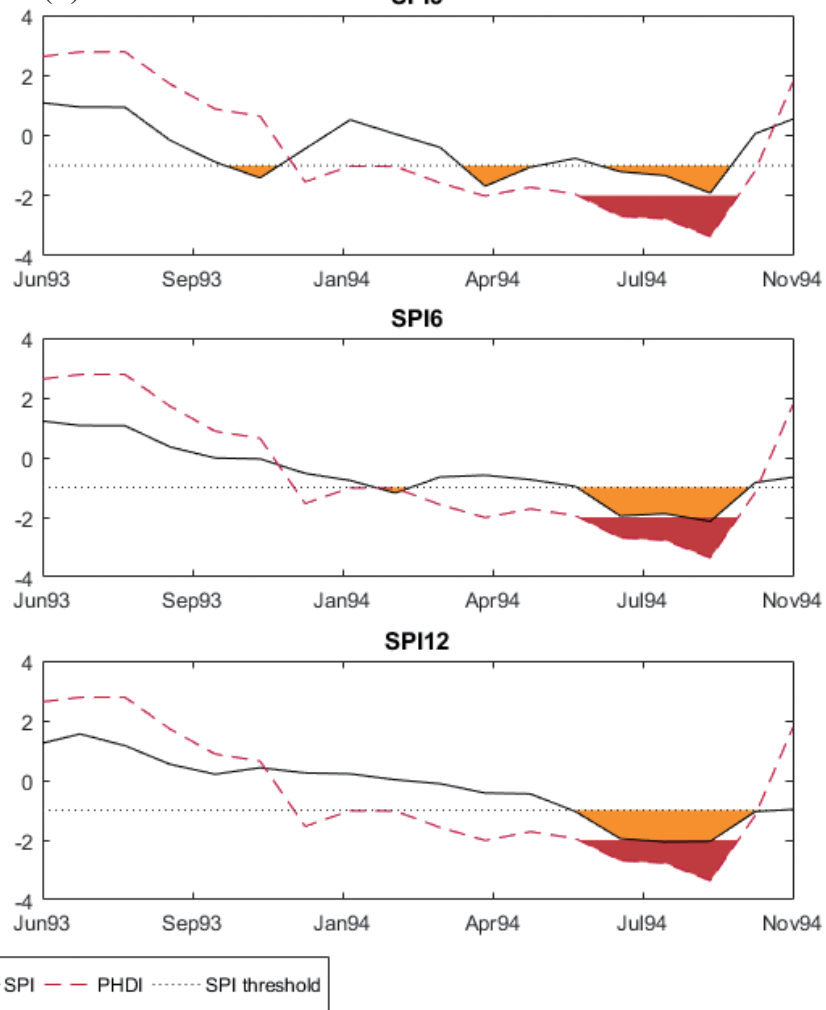

Fig. 3. Example of drought propagation events at Sokcho station. MDrought indicates a meteorological drought detected by SPI, while HDrought indicate a hydrological drought by PHDI. (a) 1988 Drought; (b) 1994 Drought. 
3-month SPI drought event shown in Fig. 3a) were pooled when the drought event reoccurred for at least 2 months and SPI values of inter drought event time were less than zero.

The quantitative characteristics of meteorological and hydrological drought, such as number of drought events and mean duration of drought events, are summarized in Table 2. Drought events became fewer and longer when drought propagated from 3-month SPI to PHDI. These drought properties have been also shown in various studies (Tallaksen et al. 2009; Van Loon and Van Lanen 2012; Wong et al. 2013; Barker et al. 2016).

\subsection{Drought Propagation Probability}

We estimated the drought propagation probability conditioned on the hydrological drought PHDI occurrence. Since hydrological drought is a slower developing phenomenon than 3- and 6-month SPI in South Korea, when we developed the drought propagation occurrence probability, we were limited to consideration of the classical rainfall deficit drought caused by a prolonged lack of precipitation and developed into a hydrological drought. In the previous section, we identified propagation events of classical rainfall deficit drought (Fig. 2) and identified the type of drought propagation (Fig. 3). From Figs. 2 and 3, the 3- or 6-month SPI caused the drought onset of PHDI which lasted during the drought condition of SPI.

We also compared the meteorological and hydrological drought events at specific stations. For example, Table 3 shows six meteorological drought events and four hydrological drought events at Sokcho. Meteorological drought occurred in April 1988 and continued until hydrological drought onset in May 1998. The meteorological drought event ended in August 1988 while hydrological drought ended in December 1988. The hydrological drought events in 1991, 1994, and 1995 also showed similar drought propagation as summarized in Table 3 . We found that hydrological drought events usually developed after meteorological drought at other stations as well. This indicates that meteorological drought during hydrological drought onset

Table 2. Drought characteristics of 3- and 6-month SPI and PHDI between 1973 and 2015.

\begin{tabular}{c|cccc}
\hline Station & Properties & SPI 3 & SPI 6 & PHDI \\
\hline \multirow{2}{*}{ Seoul } & No. of drought event & 32 & 25 & 15 \\
& Mean duration (month) & 3.00 & 3.16 & 7.67 \\
\hline \multirow{2}{*}{ Daejeon } & No. of drought event & 33 & 27 & 12 \\
& Mean duration (month) & 2.79 & 3.81 & 9.17 \\
\hline \multirow{2}{*}{ Gwangju } & No. of drought event & 32 & 24 & 12 \\
& Mean duration (month) & 2.44 & 4.33 & 8.92 \\
\hline \multirow{3}{*}{ Yeongju } & No. of drought event & 41 & 25 & 16 \\
& Mean duration (month) & 2.24 & 3.72 & 6.00 \\
\hline \multirow{3}{*}{ Busan } & No. of drought event & 38 & 29 & 17 \\
& Mean duration (month) & 2.05 & 3.00 & 5.53 \\
\hline \multirow{2}{*}{ Wonju } & No. of drought event & 35 & 25 & 11 \\
& Mean duration (month) & 2.63 & 3.24 & 7.91 \\
\hline \multirow{2}{*}{ Average of 35 stations } & No. of drought event & 36.09 & 24.91 & 14.20 \\
& Mean duration (month) & 2.51 & 3.79 & 7.26 \\
\hline
\end{tabular}

Table 3. Comparison of meteorological and hydrological drought events at Sokcho station.

\begin{tabular}{cc|cc|c}
\hline \multicolumn{2}{c|}{ Meteorological drought $\mathbf{( 3}$ month-SPI) } & \multicolumn{2}{|c|}{ Hydrological drought (PHDI) } & \multirow{2}{*}{ Propagation occurrence } \\
\cline { 1 - 3 } Beginning date & Ending date & Beginning date & Ending date & \\
$1987-01$ & $1987-01$ & & & \\
$1988-04$ & $1988-08$ & $1988-05$ & $1988-12$ & Occur \\
$1991-06$ & $1991-11$ & $1991-09$ & $1991-11$ & Occur \\
$1993-11$ & $1993-11$ & & & \\
$1994-04$ & $1994-09$ & $1994-04$ & $1994-09$ & Occur \\
$1995-06$ & $1996-06$ & $1995-11$ & $1996-02$ & Occur \\
\hline
\end{tabular}


is the dominate factor for identifying drought propagation.

Before estimating the drought propagation occurrence probability, it is necessary to determine whether meteorological drought is a dry condition when hydrological drought begins. First, the meteorological drought condition probability during hydrological drought onset was calculated using Eq. (7), based on conditional probability theory.

$P\left(M_{j} \in C_{m} \mid H_{j}\right)=\frac{\sum_{j=1}^{n} \sum_{m=1}^{3}\left(H_{j}, M_{j, m}\right)}{\sum_{j=1}^{n} H_{j}}$

where, $H_{j}$ is the hydrological drought onset event and $n$ is the number of hydrological drought events. $M_{j, m}$ is the meteorological condition when hydrological drought has occurred. $C_{m}$ is the drought class: $C_{0}=$ no drought, $C_{1}=$ moderate, $C_{2}=$ severe, $C_{3}=$ extreme. In this study, the meteorological drought occurrence state was defined by $C_{1}, C_{2}$, and $C_{3}$. The computation process of Eq. (7) is the same as with the drought transition probabilities and the probability matrix is shown in Table 4.

Table 4 shows the probability that meteorological drought occurred in the case of hydrological drought onset at representative six stations and the average of the 35 stations, which had a probability of 0.839 in the 3-month SPI and 0.721 in the 6-month SPI, respectively. This means that $72-84 \%$ of hydrological drought events occurred with meteorological drought. In addition, Fig. 4 presents the meteorological drought occurrence probability in the case of hydrological drought onset in South Korea. The 3-month SPI showed higher probability than 6-month SPI, while Gangwon-do district had low probability with 3- and 6-month SPI.

From the hydrological drought developing procedure, we estimated the probability of drought propagation occurrence using conditional probability theory. Now, we can express the propagation occurrence probability that is the transition probability from meteorological drought to hydrological drought using Eq. (8).

Table 4. Probability matrix of meteorological drought condition with hydrological drought onset.

\begin{tabular}{cccccccc}
\hline Drought index & Seoul & Daejeon & Gwangju & Yeongju & Busan & Wonju & Average of 35 stations \\
\hline SPI 3 & 0.933 & 0.833 & 0.917 & 0.938 & 0.706 & 0.909 & 0.839 \\
SPI 6 & 0.800 & 0.917 & 0.750 & 0.563 & 0.588 & 0.727 & 0.721 \\
\hline
\end{tabular}

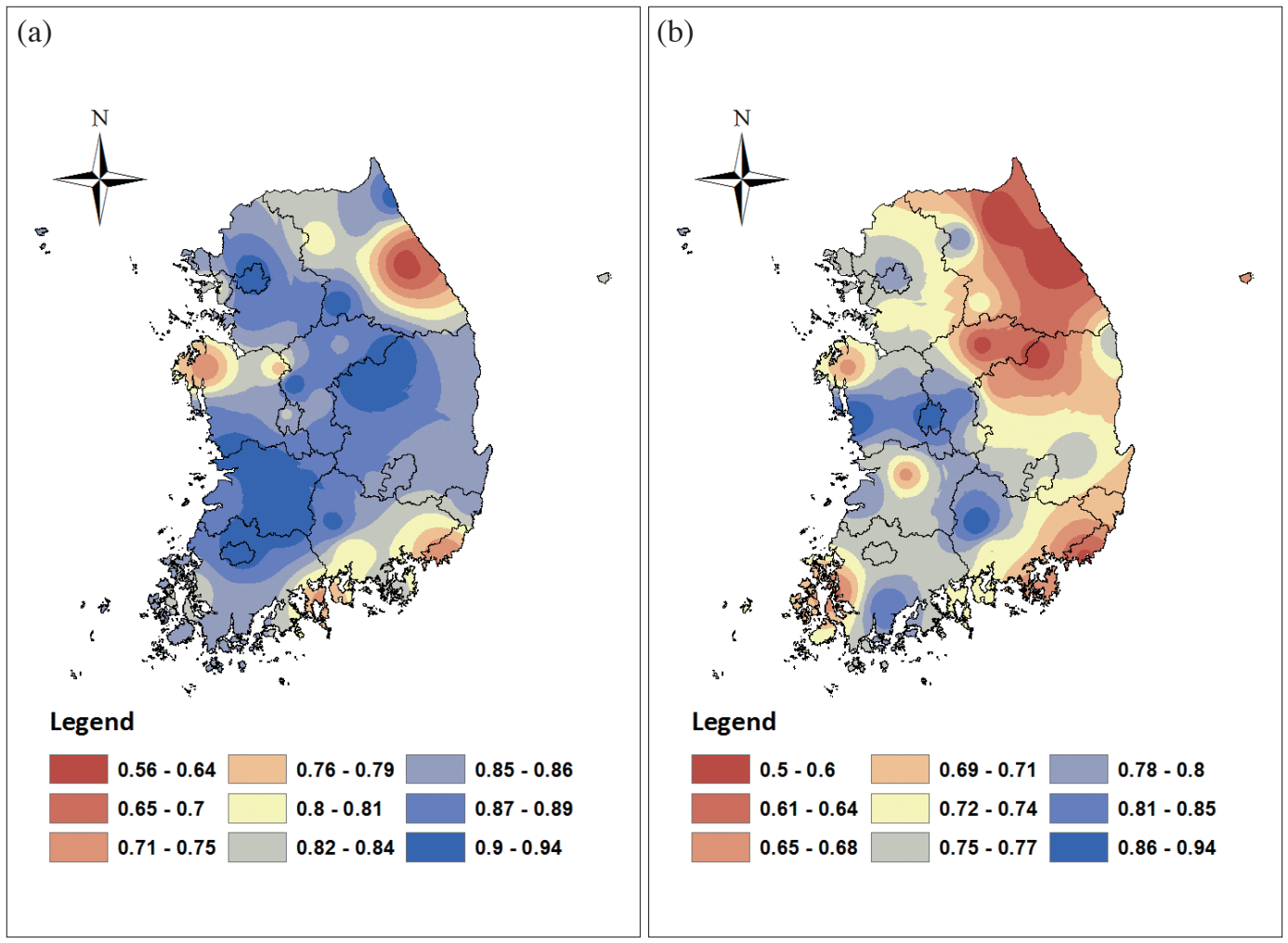

Fig. 4. Probability of meteorological drought occurrence in the case of hydrological drought onset. (a) 3-month SPI; (b) 6-month SPI. 
$P\left(H_{i} \in C_{m} \mid M_{i}\right)=\frac{\sum_{i=1}^{m} \sum_{m=1}^{3}\left(H_{i, m}, M_{i}\right)}{\sum_{i=1}^{n} M_{i}}$

where, $M_{i}$ is the meteorological drought event and $m$ is the number of meteorological drought event. $H_{i, m}$ is the hydrological drought event during the meteorological drought occurrence. The propagation occurrence probabilities of the SPI values are shown in Table 5 . There was a probability of 0.3 - 0.6 for drought events of 3- and 6-month SPI developing into hydrological drought. Overall, in South Korea, 33.3\% of meteorological drought events propagated to hydrological drought. The drought propagation probability in South Korea is illustrated in Fig. 5. In Fig. 5a, in which Chungcheongnam-do and Gyeonggi-do show high drought propagation probability, meaning that they have a higher chance of meteorological drought developing into hydrological drought than other districts. In Fig. 5b, Chungcheongnam-do, Gyeonggi-do and upper Gyeonsangbuk- do districts show high drought propagation probability with the 6-month SPI providing higher propagation probability values than 3 -month SPI.

We identified the drought characteristics (duration, severity, intensity) of meteorological drought that propagated to hydrological drought. Duration is the lasting period of a drought event, severity is the sum of drought indicator values during the drought event, and intensity is the severity divided by duration. Drought properties of meteorological drought (3- and 6-month SPI) event in accordance with the development of hydrological drought are displayed in Fig. 6.

Meteorological drought, which has a long duration and strong severity, tends to propagate toward hydrological drought, as shown in Fig. 6. However, this study identified that a drought propagation event happens when a hydrological drought occurred during meteorological drought conditions, although other different drought propagation procedures were not considered. If a new type of propagation can be identified, we can provide a more accurate approximation of the occurrence probability of drought propagation.

Table 5. Propagation occurrence probability from 3- and 6-month SPI.

\begin{tabular}{cccccccc}
\hline Drought index & Seoul & Daejeon & Gwangju & Yeongju & Busan & Wonju & Average of 35 stations \\
\hline SPI 3 & 0.438 & 0.303 & 0.344 & 0.366 & 0.316 & 0.286 & 0.330 \\
SPI 6 & 0.560 & 0.370 & 0.458 & 0.600 & 0.414 & 0.400 & 0.480 \\
\hline
\end{tabular}

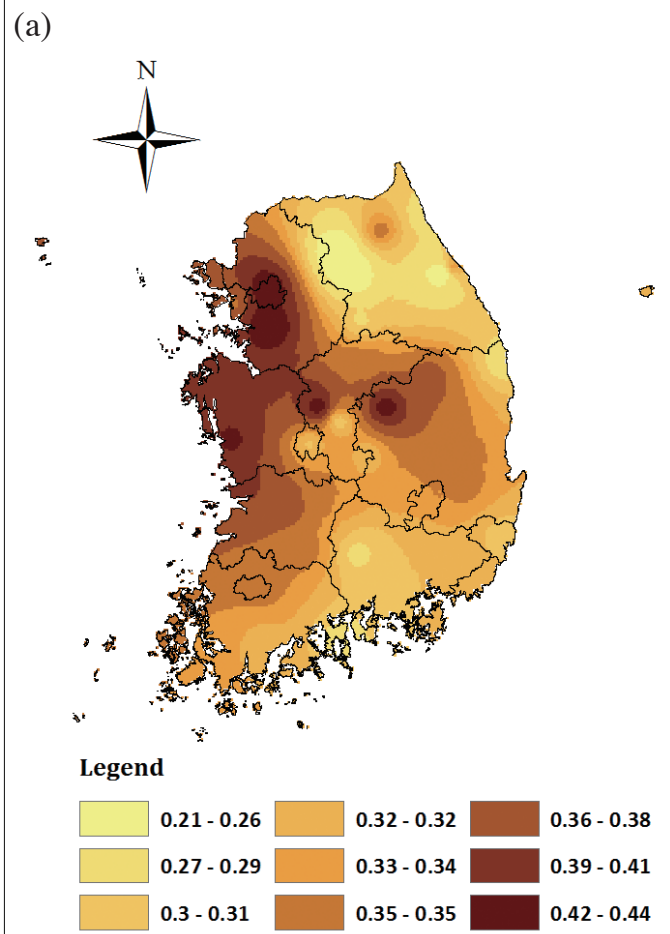

(b)
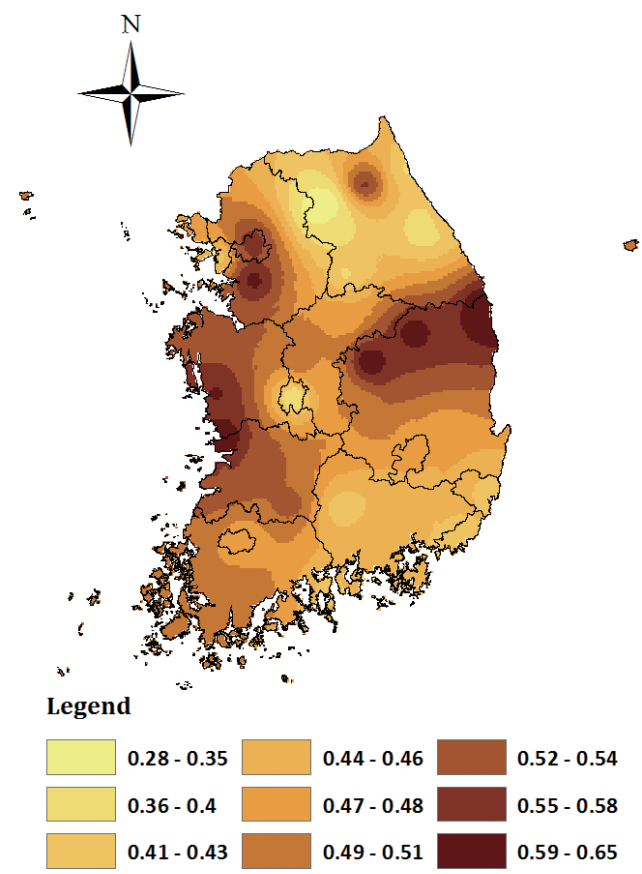

Fig. 5. Probability of drought propagation from meteorological to hydrological drought. (a) 3-month SPI; (b) 6-month SPI. 

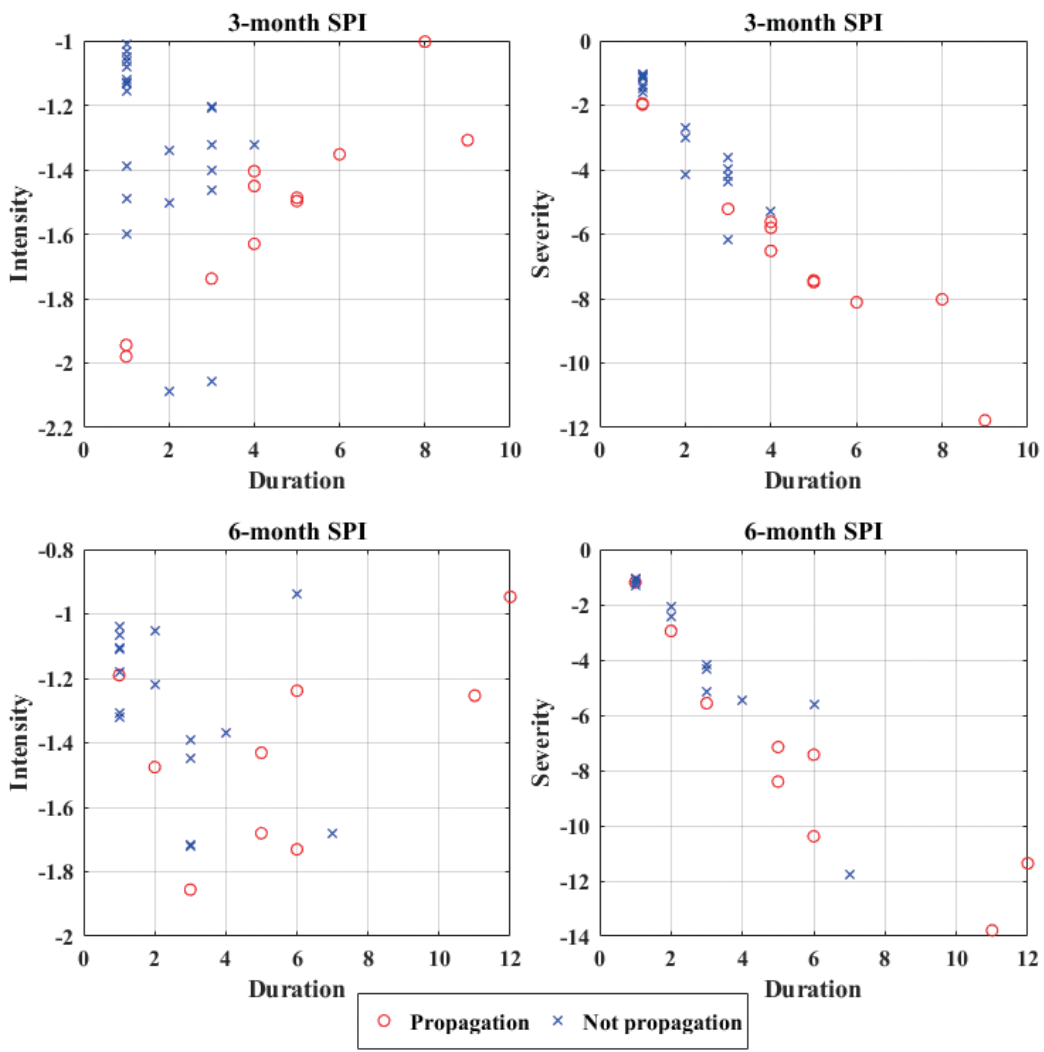

Fig. 6. Characteristics of meteorological drought that induced drought propagation at Gangneung station.

\section{CONCLUDING REMARKS}

All types of drought originate from a precipitation deficiency, which means that meteorological droughts become a starting point for agricultural and hydrological drought development (Van Loon 2013). Thus, understanding how meteorological drought evolves into agricultural and hydrological drought is important for developing efficient drought management. This study addressed the drought propagation from meteorological to hydrological drought using drought indices and estimated the drought propagation occurrence probability in South Korea. We applied the PHDI to assess the hydrological drought since enough reliable streamflow data has not been retained in South Korea.

By comparing different types of drought indices, we investigated the link between the drought indices. First, overall hydrological drought (PHDI) has occurred after or with meteorological drought (3- or 6-month SPI), and the observed results easily explained the drought propagation phenomenon. Moreover, the meteorological drought state probability was calculated when hydrological drought started. There was a 0.84 probability for 3 -month SPI and 0.72 for 6 -month SPI to bring meteorological drought with hydrological drought. Finally, we estimated the occurrence probability of drought propagation that is the probability of hydrological drought occurrence when meteorological drought starts. And we also found that propagated drought events exhibited long durations and strong severity. The propagated 3- or 6 month-SPI has a duration over three months and a severity of 5 .

The main limitation of this study is that we cannot consider all kinds of drought propagation; however, this paper provides a new approach to analyze drought propagation using conditional propagation theory and to estimate the occurrence probability of drought propagation. The propagation occurrence probability can be applied in hydrological drought management, preparing drought countermeasures when meteorological drought occurs and forecasting hydrological drought using meteorological drought indicators.

Acknowledgements This research was supported by a grant from the Water Management Research Program (16AWMPB079625-03) funded by the Ministry of Land, Infrastructure and Transport, Republic of Korea.

\section{REFERENCES}

Barker, L. J., J. Hannaford, A. Chiverton, and C. Svensson, 2016: From meteorological to hydrological drought using standardised indicators. Hydrol. Earth Syst. Sci., 12, 12827-12875, doi: 10.5194/hessd-12-12827-2015. [Link]

Belayneh, A., J. Adamowski, B. Khalil, and B. 
Ozga-Zielinski, 2014: Long-term SPI drought forecasting in the Awash River Basin in Ethiopia using wavelet neural network and wavelet support vector regression models. J. Hydrol., 508, 418-429, doi: 10.1016/j.jhydrol.2013.10.052. [Link]

Changnon, S. A., 1987: Detecting drought conditions in Illinois. Illinois State Water Survey, Champaign, Circular 169, $34 \mathrm{pp}$.

Dai, A., 2011: Drought under global warming: A review. WIREs Clim. Change, 2, 45-65, doi: 10.1002/wcc.81. [Link]

Guttman, N. B., 1991: A sensitivity analysis of the Palmer hydrologic drought index. J. Am. Water Resour. Assoc., 27, 797-807, doi: 10.1111/j.1752-1688.1991. tb01478.x. [Link]

Haslinger, K., D. Koffler, W. Schöner, and G. Laaha, 2014: Exploring the link between meteorological drought and streamflow: Effects of climate-catchment interaction. Water Resour. Res., 50, 2468-2487, doi: 10.1002/2013wr015051. [Link]

Heim, R. R., 2002: A review of twentieth-century drought indices used in the United States. Bull. Amer. Meteorol. Soc., 83, 1149-1165, doi: 10.1175/1520-0477(200 2) $083<1149$ :arotdi $>2.3 . c o ; 2$. [Link]

Jacobi, J., D. Perrone, L. L. Duncan, and G. Hornberger, 2013: A tool for calculating the Palmer drought indices. Water Resour. Res., 49, 6086-6089, doi: 10.1002/ wrcr.20342. [Link]

Joetzjer, E., H. Douville, C. Delire, P. Ciais, B. Decharme, and S. Tyteca, 2013: Hydrologic benchmarking of meteorological drought indices at interannual to climate change timescales: a case study over the Amazon and Mississippi river basins. Hydrol. Earth Syst. Sci., 17, 4885-4895, doi: 10.5194/hess-17-4885-2013. [Link]

Keyantash, J. and J. A. Dracup, 2002: The quantification of drought: an evaluation of drought indices. Bull. Amer. Meteorol. Soc., 83, 1167-1180, doi: 10.1175/1520-047 7(2002)083<1191:tqodae>2.3.co;2. [Link]

Kwak, J., D. Kim, S. Kim, V. P. Singh, and H. Kim, 2014: Hydrological drought analysis in Namhan river basin, Korea. J. Hydrol. Eng., 19, doi: 10.1061/(asce) he.1943-5584.0000889. [Link]

Kwon, H. H., U. Lall, and S. J. Kim, 2016: The unusual 2013-2015 drought in South Korea in the context of a multicentury precipitation record: Inferences from a nonstationary, multivariate, Bayesian copula model. Geophys. Res. Lett., 43, 8534-8544, doi: 10.1002/2016g1070270. [Link]

McKee, T. B., N. J. Doesken, and J. Kleist, 1993: The relationship of drought frequency and duration to time scales. Proceedings of the Eighth Conference on Applied Climatology, American Meteorological Society, Anaheim, California, 179-183.

Melo, D. C. D. and E. Wendland, 2016: Hydrological system time lag responses to meteorological shifts. $R B R H, \mathbf{2 1}$, 766-776, doi: 10.1590/2318-0331.011616083. [Link]

Min, S. K., W. T. Kwon, E. H. Park, and Y. Choi, 2003: Spatial and temporal comparisons of droughts over Korea with East Asia. Int. J. Climatol., 23, 223-233, doi: $10.1002 /$ joc. 872 . [Link]

Palmer, W. C., 1965: Meteorological drought. Weather Bureau Research Paper No. 45, US Department of Commerce, Washington, DC.

Tallaksen, L. M., H. Hisdal, and H. A. J. Van Lanen, 2009: Space-time modelling of catchment scale drought characteristics. J. Hydrol., 375, 363-372, doi: 10.1016/j. jhydrol.2009.06.032. [Link]

Thomas, T., R. K. Jaiswal, P. C. Nayak, and N. C. Ghosh, 2015: Comprehensive evaluation of the changing drought characteristics in Bundelkhand region of Central India. Meteorol. Atmos. Phys., 127, 163-182, doi: 10.1007/s00703-014-0361-1. [Link]

Van Lanen, H. A. J., 2006: Drought propagation through the hydrological cycle. Proceedings of the Fifth FRIEND World Conference, IAHS-AISH Publication 308, Havana, Cuba, 122-127.

Van Loon, A. F., 2013: On the propagation of drought. How climate and catchment characteristics influence hydrological drought development and recovery. Ph.D. Thesis, Wageningen University.

Van Loon, A. F., 2015: Hydrological drought explained. WIREs Water, 2, 359-392, doi: 10.1002/wat2.1085. [Link]

Van Loon, A. F. and H. A. J. Van Lanen, 2012: A process-based typology of hydrological drought. Hydrol. Earth Syst. Sci., 16, 1915-1946, doi: 10.5194/ hessd-8-11413-2011. [Link]

Vicente-Serrano, S. M., S. Beguería, J. Lorenzo-Lacruz, J. J. Camarero, J. I. López-Moreno, C. Azorin-Molina, J. Revuelto, E. Morán-Tejeda, and A. Sanchez-Lorenzo, 2012: Performance of drought indices for ecological, agricultural, and hydrological applications. Earth Interact., 16, 1-27, doi: 10.1175/2012ei000434.1. [Link]

Wang, W., M. W. Ertsen, M. D. Svoboda, and M. Hafeez, 2016: Propagation of drought: From meteorological drought to agricultural and hydrological drought. $A d v$. Meteorol., 2016, 1-5, doi: 10.1155/2016/6547209. [Link]

Weber, L. and L. Kkemdirim, 1998: Palmer's drought indices revisited. Geogr. Ann. Phys. Geogr., 80, 153-172, doi: 10.1111/j.0435-3676.1998.00033.x. [Link]

Wilhite, D. A., 2000: Drought, A Global Assessment, Vol. I \& II, Routledge Hazards and Disasters Series, Routledge, London, UK.

Wilhite, D. A. and M. H. Glantz, 1985: Understanding: The drought phenomenon: The role of definitions. Water Int., 10, 111-120, doi: 10.1080/02508068508686328. [Link] 
Wong, G., H. A. J. Van Lanen, and P. J. J. F. Torfs, 2013: Probabilistic analysis of hydrological drought characteristics using meteorological drought. Hydrolog. Sci. J., 58, 253-270, doi: 10.1080/02626667.2012.753147. [Link]

Yoo, J., H. H. Kwon, B. J. So, B. Rajagopalan, and T. W. Kim, 2015: Identifying the role of typhoons as drought busters in South Korea based on hidden Markov chain models. Geophys. Res. Lett., 42, 2797-2804, doi: 10.1002/2015g1063753. [Link]

Zargar, A., R. Sadiq, B. Naser, and F. I. Khan, 2011: A review of drought indices. Environ. Rev., 19, 333-349, doi: 10.1139/a11-013. [Link]

Zhai, J., B. Su, V. Krysanova, T. Vetter, C. Gao, and T.
Jiang, 2010: Spatial variation and trends in PDSI and SPI indices and their relation to streamflow in 10 large regions of China. J. Climate, 23, 649-663, doi: 10.1175/2009jcli2968.1. [Link]

Zhao, L., A. Lyu, J. Wu, M. Hayes, Z. Tang, B. He, J. Liu, and M. Liu, 2014: Impact of meteorological drought on streamflow drought in Jinghe River Basin of China. Chin. Geogr. Sci., 24, 694-705, doi: 10.1007/s11769014-0726-x. [Link]

Zhu, Y., W. Wang, V.P. Singh, and Y. Liu, 2016: Combined use of meteorological drought indices at multi-time scales for improving hydrological drought detection. Sci. Total Environ., 571, 1058-1068, doi: 10.1016/j. scitotenv.2016.07.096. [Link] 